\title{
ENGAGEMENT STANCE IN THE ILLEGITIMATE DISCOURSE PRACTICE ${ }^{1}$
}

\author{
Pavel A. Katyshev \\ Pushkin State Russian Language Institute, Moscow, Russia \\ Natalya A. Bozhenkova \\ Pushkin State Russian Language Institute, Moscow, Russia
}

\begin{abstract}
The paper deals with an interpersonal approach to the study of mediated political communication, that is aimed at the description of text impact capacity considered as tool of influence on group characteristic of an engaged object through the acceptance of the involving person's attitudes. The goal of the study was reached through rhetorical analysis, the methodology of critical discourse analysis and sociolinguistic theory of membership categorization. The concept of "engagement stance" is introduced and considered as metadiscourse characteristics of a communicative artefact reflecting the initiative of the subject (an initiator of engagement) whose purpose is to involve the audience to the ideology and practice of a terrorist organization. The study takes into account linguisticparametric signs, significant for law enforcement practice, which make it possible to externalize the mindset to involve others in committing the crimes of an extremist (terrorist) orientation and to identify its verbal indicators. Rhetorical analysis of the engagement stance proves, that adaptation of the text type depends on the communicative intentions of the corporate author and shows text capacity for genre transformations caused by public circumstances, it is presented in the following characteristics: a) asymmetry as an interactional feature of the corporate subject and the object of an engagement action; b) perception of the corporate subject as an absolute truth holder, whose views acceptance is positioned as the only right decision for the object; c) the regulatory nature of the message aimed at receiving responses controlled by the sender (the corporate subject of an engagement).

Key words: engagement, engagement stance, critical discourse analysis, membership categorization theory, metadiscourse, terrorist organization, genre.

Citation. Katyshev P.A., Bozhenkova N.A. Engagement Stance in the Illegitimate Discourse Practice. Vestnik Volgogradskogo gosudarstvennogo universiteta. Seriya 2. Yazykoznanie [Science Journal of Volgograd State University. Linguistics], 2020, vol. 19, no. 5, pp. 173-182. (in Russian). DOI: https://doi.org/10.15688/jvolsu2.2020.5.15

\section{ПОЗИЦИЯ ВОВЛЕЧЕНИЯ В НЕЛЕГИТИМНОЙ ДИСКУРСИВНОЙ ПРАКТИКЕ 1}

\section{Павел Алексеевич Катышев}

Государственный институт русского языка им. А.С. Пушкина, г. Москва, Россия

\section{Наталья Александровна Боженкова}

Государственный институт русского языка им. А.С. Пушкина, г. Москва, Россия

\footnotetext{
Аннотация. В статье представлен интерперсональный подход к изучению опосредованной политической коммуникации. Применение риторического анализа, учитывающего методологию критических исследований дискурса и социолингвистическую теорию категоризации членства, реализует цель работы - описать воздействующий потенциал текста как способа изменения групповых характеристик объекта вовлечения на основе принятия им установок вовлекателя. Для достижения поставленной цели вводится понятие «позиция вовлечения», посредством которого описываются метадискурсивные характеристики
} 
коммуникативного артефакта, отражающие инициативу адресанта, направленную на приобщение аудитории к идеологии и практике террористической организации. Одновременно учитываются значимые для правоприменительной практики лингвопараметрические признаки, позволяющие экстернализировать установку на вовлечение в совершение преступлений экстремистской (террористической) направленности и определить ее вербальные показатели. Анализ позиции вовлечения показал, что приспособление текстотипа к коммуникативным намерениям корпоративного автора демонстрирует ситуативную предрасположенность жанрового ресурса к преобразованию, вследствие чего результирующий текст эксплицирует: а) асимметрию как черту взаимодействия корпоративного субъекта и адресата; б) представление о корпоративном субъекте как носителе готовой истины, принятие которой является для адресата единственно верным решением; в) регулирующий характер сообщения, направленный на получение реакций, контролируемых адресантом.

Ключевые слова: вовлечение, позиция вовлечения, критический дискурс-анализ, теория категоризации членства, метадискурс, террористическая организация, жанр.

Цитирование. Катышев П. А., Боженкова Н. А. Позиция вовлечения в нелегитимной дискурсивной практике // Вестник Волгоградского государственного университета. Серия 2, Языкознание. - 2020. - Т. 19, № 5. - C. 173-182. - DOI: https://doi.org/10.15688/jvolsu2.2020.5.15

\section{К постановке проблемы}

Вовлечение как степень участия интерактантов в коммуникации [Гуляева, 2016] составляет сущность межличностного диалогического общения. Однако установка на включение индивида в разговор, а также в различные виды социально-предметной деятельности характеризует не только непосредственную коммуникацию, но и опосредованную [Engagement..., 2019; Hyland, Jiang, 2016; Suau-Jiménez, Dolón, 2007]. Более того, состояние вовлеченности определяет коммуникативный обмен между субъектами, имеющими как одинаковый, так и неравный социальноролевой статус [Боженкова и др., 2019; Araeva et al., 2018].

Политический дискурс как сфера приложения субъектов, наделенных властными полномочиями или обладающих претензиями на власть, предполагает реализацию сценариев вовлечения, определяющих взаимодействие между разностатусными участниками политического процесса. Для его эффективного осуществления могут привлекаться метадискурсивные техники, соответствующие положению институционального субъекта на политической арене ${ }^{2}$. В данной статье внимание сосредоточено на таких сценариях вовлечения, которые используются идеологами террористических организаций для продвижения интересов радикального сообщества. В этом контексте будут рассмотрены сценарии фонового вовлечения и вовлечения-расположения (склонения). В первом случае вовле- чение составляет фон для дальнейших манипуляций с вовлекаемым (адресант, воздействуя на реципиента, исходит из групповой идентичности с ним). Во втором случае субъект вовлечения отказывает вовлекаемому в равенстве по статусу, осведомленности, мировоззренческой зрелости и т. д., поэтому вовлечение приобретает черты расположения, направленного на формирование у адресата готовности разделить с вовлекающим какие-либо взгляды на что-либо, действовать совместно с ним или в соответствии с его побуждениями и т. д. Полагаем, что различие в способах организации рассматриваемой дискурсивной деятельности зависит как от позиции, занимаемой адресантом в отношении вовлечения, так и от степени погруженности вовлекаемого в организационный (корпоративный) контекст.

Указанные обстоятельства, несомненно, свидетельствуют об актуальности исследований политического дискурса с учетом практик вовлечения аут-групп и сплочения членов ин-группы, что в конечном счете позволит представить политические феномены сквозь призму институциональных культур вовлечения. Отметим, что степень изученности инклюзивных феноменов зависит от легитимности вовлекателя. Так, коммуникативносемиотические инструменты электоральной риторики, определяющей участие избирателей в предвыборных кампаниях, изучены лучше, нежели способы вовлечения в деятельность запрещенных в государстве сообществ (организаций). Вместе с тем уровень и характер исследованности явлений инклюзии подкреп- 
ляется экспертной практикой по делам о подстрекательстве к деятельности экстремистской (террористической) направленности, в результате чего предпринимаются усилия по судебно-лингвистической параметризации вовлечения, описанию его коммуникативно-семиотических механизмов, характеризующих, прежде всего, устную интеракцию представителей террористических сообществ [Хазимуллина, 2016]. В этой связи известные нам модели описания нелегальных практик вовлечения требуют корректировки с учетом особенностей опосредованной коммуникации, поскольку остается открытым вопрос о том, как исследовать (разбирать) проявления подстрекательства (в частности, побуждение к сближению с нелегальной группой), если непосредственный контакт между лицами отсутствует.

Цель статьи заключается в том, чтобы представить вовлечение - а именно побуждение к участию кого-либо в деятельности экстремистской (террористической) направленности - как слагаемое тех усилий, которые предпринимает институциональный вовлекатель (адресант) для мотивации вовлекаемого (адресата). При этом деятельность вовлекателя, направленная на придание опосредованной коммуникации диалогических характеристик, рассматривается в аспекте реализуемого адресантом сценария взаимодействия с адресатом. Это позволяет диагностировать в исследуемом объекте определенную позицию вовлечения как некий дискурсивно значимый антропокомпонент (то есть систему дискурсивных параметров и процедур), благодаря которому порождается текст, создающий условия для сближения точки зрения реципиента с точкой зрения адресанта.

\section{Концептуальные предпосылки исследования}

Асимметрия социальных позиций особенно остро ощущается при рассмотрении таких дискурсивных практик, которые применяются агентами нелегальных организаций в отношении управляемой аудитории. В российском уголовном законодательстве понятийным ядром категории вовлечения выступает идея о целенаправленной деятельности, ори- ентированной на формирование у объекта воздействия решимости или готовности участвовать в совершении общественно опасного деяния [Селиванова, 2010]. При этом учитывается, что подстрекательство к деятельности в интересах нелегальной группы может быть реализовано и дискурсивным путем (см., в частности, п. 14 постановления Пленума Верховного суда РФ от 09.02.12 № 1 «О некоторых вопросах судебной практики по уголовным делам о преступлениях террористической направленности»). Иными словами, в сфере права сформировано представление о вовлечении как социальном, когнитивном и дискурсивном феномене, в силу чего понятийные аспекты рассматриваемой аналитической категории предполагают включение в дефиницию ряда признаков, свидетельствующих:

1) об особенностях общего социокоммуникативного контекста, ориентирующего сообщество в целеполагании и способах достижения поставленных целей;

2) о стадиях инклюзивного воздействия, обеспечивающих укоренение установки на пополнение и сплочение сообщества;

3) о метадискурсивном (интерперсональном) устройстве коммуникации как:

- институциональной культуре - системе моделей поведения, принятых в нелегальном сообществе;

- дискурсивной практике вовлечения, определяющей закономерности использования коммуникативно-семиотических средств с учетом дискурсивных процедур, направленных на конструирование взаимодействия между адресантом и адресатом;

- дискурсивном строе - совокупности всех типов дискурсов, которые используются в каком-либо нелегальном сообществе для достижения инклюзивных целей.

Именно расширение толкования интерперсональной коммуникации до некой семиотической практики обусловливает введение регуляционного параметра «позиция, занимаемая адресантом в отношении вовлечения», или позиция вовлечения. Через нее определяется, в частности, то, как адресант (автор текста) представляет себя и другого в качестве участников процесса социальной интеракции. Данный параметр имеет комплексный характер и устанавливает процедуры, связанные: 
- с фокусировкой адресанта на инклюзивной интенции;

- отбором такого пропозиционального содержания высказывания, которое имеет отсылки к сфере вовлечения;

- использованием коммуникативно-семиотических средств, направленных на выравнивание, сближение адресата и адресантаподстрекателя.

Кроме того, в состав позиции вовлечения (для более частных случаев) могут быть включены процедуры, касающиеся:

- выбора адресантом целевой аудитории и способов ее репрезентации;

- распределения статусов и ролей адресанта и адресата в условиях совершаемого коммуникативного действия;

- установления определенного отношения к реципиенту;

- указания на степень и характер близости сообщаемого и корпоративных (организационных) ценностей адресанту и реципиенту (их отождествления с источником сообщения или расподобления с ним);

- отнесения к членам референтной («правильной») группы реципиента с возможным указанием: а) на ее предпочтения и ценности; б) способы вхождения в нее; в) важные для нее личностные качества; г) условия членства; д) обязательства пребывания в ней.

Идея выделения параметра «позиция вовлечения» и его составляющих восходит к разнообразным теоретическим конструктам, связанным с осмыслением феномена коллективной деятельности:

- металингвистической концепции М.М. Бахтина об интертекстовых феноменах, обладающих двойной референцией к чужому слову (в том числе другой смысловой позиции) и авторскому отношению к нему [Бахтин, 1979, с. 212-215];

- интерперсональной концепции меmaдискурса К. Хайланда, позволяющей рассмотреть письменный текст как практику использования языка, обусловленную фактором реципиента [Hyland, 2005; 2017];

- ряду аналитических категорий, в числе которых:

а) интерперсональность и близость как понятия, позволяющие рассматривать формирование и формулирование текстового содержания в связи с его ориентацией на сознание определенного реципиента; при этом под близостью понимается такое свойство текстовой категории образа автора, которое определяет причастность субъекта к содержанию сообщения и принадлежность к представляемому им сообществу, а под интерперсональностью - предрасположенность автора текста к моделированию взаимодействия с читателем с целью передачи сообщаемого [Hyland, 2010];

б) сообщество как термин, обозначающий самоорганизованную группу, соединенную убеждениями, интересами и обязательствами [Bhatia, 2011, p. 127] и сформированную посредством набора правил и процедур, которые допускают лиц к членству в группе и тем самым к получению в ней должностей [Jayyusi, 1984, p. 26]; инклюзивное сообщество - термин, определяющий такую группу, которая преследует цели, соответствующие благу, достигаемому и осваиваемому сообща, а потому расширяет свой состав за счет включения с помощью агитации, уговоров и др. действий новых членов [Олсон, 1995, с. 94];

в) референтная групnа - понятие, характеризующее реальную или воображаемую социальную общность, выступающую для индивида эталоном, образцом для подражания, источником формирования социальных норм и ценностных ориентаций [Кравченко, Поликарпова, Науменко, 2019].

Таким образом, дискурсивная практика вовлечения в текстах письменной коммуникации предполагает моделирование интеракции, инициируемой одним из коммуникантов (адресантом), и диктуется процедурами, входящими в комплексный параметр позиции вовлечения.

\section{Материал и методы исследования}

Данные для изучения взяты из корпуса письменных текстов, созданных с целью передачи и продвижения идеологии террористической организации «Хизб ут-Тахрир альИслами», признанной запрещенной на территории Российской Федерации решением Верховного суда от 14 февраля 2003 года. Доступ к текстам получен в ходе проведения экспертных мероприятий (назначенных исследова- 
ний и экспертиз). Обоснование релевантности комплекса признаков, представляющих позицию вовлечения, осуществляется с опорой на критический анализ публикации «Диалог в аль-Хараме», размещенной в журнале «АльВаъй» (2009, № 274) (далее - Объект). Это издание публикует материалы, которые содержат информацию, относящуюся к идеологии и деятельности террористической организации «Хизб ут-Тахрир аль-Ислами». Некоторые из номеров журнала внесены в Федеральный список экстремистских материалов (по данным на 28.08.2019 рассматриваемый номер не внесен в Федеральный список экстремистских материалов); журнал издается в том числе на русском языке. Публикация по форме представляет собой жанр сократического диалога; вербальная информация организована в виде нарратива, передается от лица рассказчика, излагающего содержание беседы, которая состоялась у него во время паломничества в Мекку. По коммуникативной цели анализируемый текст является императивным (агитационно-инструктирующим). Его характерной стилевой чертой выступает интердискурсивность, связанная с заимствованием жанра сократического диалога и его адаптацией к задачам дискурсивной практики вовлечения, внедренной в деятельность радикальной организации.

Переориентация жанра, его использование для решения политических задач указывают на многомерную организацию речевого вовлечения (и шире - взаимодействия), осушествляемого в условиях опосредованной письменной коммуникации. Поэтому анализ такого воздействия требует подходящей методологии, которая складывается не только из общей методики коммуникативно-риторического анализа с его вниманием к фактору адресата, но и из специализированных процедур критического дискурс-анализа и анализа социальной категоризации.

1. Критический дискурс-аналитический подход позволяет рассмотреть текст как средство доступа к социально-политическим явлениям и отношениям, связанным с деятельностью политического субъекта внутри и вне созданных им институциональных структур (В.К. и А. Бхатия, Р. Водак, Т.А. ван Дейка, Н. Фэрклафа). Применение критического дискурс-анализа дает возможность: охарактеризовать позицию, занимаемую адресантом в отношении (со)участия реципиента в деятельности организации; представить жанровые признаки высказывания (как и другие коммуникативно-семиотические средства) в качестве показателей интерперсональности асимметричного типа.

2. Агональный характер института политики, по словам А. Бхатия, порождает множество разграничительных категорий, посредством которых устанавливается приоритет одной из версий реальности над другими [Bhatia, 2011, p. 121]. Данная категоризация может приводить к тому, что одна группа способна заявить о своем абсолютном праве на власть. Поэтому для выявления намерений и идеологии группы, создающей и распространяющей свои представления о реальности и обстоятельствах членства в сообществе, используются отдельные принципы и процедуры анализа социальной категоризации (Л. Джайюси, Х. Сакс, Э.А. Щеглофф). Так, рассмотрение социальной категоризации, реализуемой через дискурс, состоит, как показано исследователями, из описания процедур, необходимых людям для осмысления деятельности других людей, и акцентирует внимание на прагматическом компоненте, поскольку ориентируется на практические действия, позволяющие людям отделять свои моральные, социальные и религиозные характеристики от чужих [Leudar, Marsland, Nekvapil, 2004, p. 244]. Следовательно, анализ социальной категоризации можно трактовать как текстовый разбор категорий, которые используются с целью утверждения власти и идеологии некоторой группы в рамках заданных общественно-политических отношений.

\section{Результаты и обсуждение}

Целеустановка рассматриваемого высказывания коррелирует с его обращенностью к неограниченному адресату, имеющему ту же конфессиональную принадлежность, что и адресант: Пусть каждый из нас приготовится отвечать перед Аллахом... Пусть каждый из нас вспомнит о Рае и огне... Давайте... откроем страницы величия мусульман... Это означает, что индивиды, отличающиеся друг 
от друга степенью участия в деятельности группы, способны извлечь из текста смыслы, соответствующие положению адресата в организационном контексте. Учет возможных ожиданий, соотносимых с когнитивно-волевыми состояниями групп читающей аудитории, обусловливает разнообразные амплуа автора текста, способность субъекта высказывания совмещать в себе черты адресанта-агитатора и адресантаинструктора. Соответственно, Объект обладает следующими признаками, дающими представление о позиции вовлечения:

1) инклюзивная интенция адресанта совпадает с целью высказывания, которая выражается в основном тезисе как утверждение обязанности мусульман сотрудничать с организацией: ...pабота вместе с Хизб-утТахрир, с партией, которая работает для осуществления правления по законам Аллаха на земле, является фардом (то есть обязанностью мусульманина);

2) при этом информация об участии в pаботе организации входит в область действия модальности долженствования (...является фардом), чем обеспечивается включение адресата (мусульманина) в деятельность, имеющую нелегитимный характер;

3) высказывание ориентировано на тех, кто, как и автор, входит в одну конфессиональную группу, в связи с чем в фокус аргументативной ситуации выносится утверждение, что соблюдение законов ислама предполагает работу в организации;

4) адресант эксплуатирует некоторую общность апперцепции (конфессиональную, экзистенциальную, организационную) для создания условий, обеспечивающих ментальную конверсию (согласие, присоединение) реципиента либо его работу в качестве агитатора;

5) адресант выступает в качестве члена организации, от лица которой он ведет агитацию и инструктаж;

6) между адресантом и реципиентом существует прекоммуникативная дистанция, связанная с тем, что адресат не включен в группу адресанта, не обладает опытом для ведения агитации;

7) адресант и реципиент находятся в отношениях неравноправия (адресант исходит из неравенства реципиента по принадлежности к референтной группе, наделенности необходи- мыми ценностными ориентирами либо по положению в группе, сформированности компетенций и т. д.);

8) адресант искренне заинтересован в реализации своей интенции и убежден в важности ее осуществления (в тексте имеются фрагменты, передающие переживания автора относительно несправедливого миропорядка и отсутствия значительных шагов на пути возрождения былого величия ислама);

9) реципиент разделяет взгляды адресанта на наличие границ между государствами, население которых исповедует ислам, интересуется тем, как исправить сложившуюся ситуацию, характеризуется открытостью позиции в отношении сообщаемого адресантом, исходит из серьезности намерений собеседника, считает его авторитетом; вместе с тем реципиент либо не знает о путях изменения сложившейся ситуации, либо не владеет способами агитации;

10) ценность референтной группы определяется по ее особому значению для представителя конфессии: она соблюдает законь Ислама, добивается их претворения в жизнь (то есть ведет работу по установлению Халифата путем уничтожения марионеточных государств), вхождение в ее ряды cnacem om наказания Аллаха, поэтому членство в организации не только приближает индивида к коллективному благу, которое станет доступным с возрождением халифата, но и требует от последователя приложения усилий, соблюдения определенных обязательств ради достижения совместной цели;

11) адресант для воплощения агитационно-инструктирующей интенции прибегает к средствам интерперсональности, позволяющим донести до адресата интенции автора текста.

Одним из таких средств выступает использование жанра сократического диалога, макроструктура которого ситуативно преобразуется (реконтекстуализируется) для передачи идей адресанта. Иными словами, усилия автора направлены на то, чтобы трансформировать жанрообразующие признаки заимствованного ресурса, адаптировав их к обстоятельствам ситуации воздействия, в силу чего направления реконтекстуализации связаны:

- с монологизацией диалогического регистра, происходящей вследствие предъявле- 
ния одной из сторон претензий на владение готовой истиной (в рассматриваемом тексте субъект речи, совпадающий с адресантом сообщения, выступает транслятором идеологии террористической организации, планов этой партии, ее техник расположения первичной аудитории);

- наделением вовлекателя чертами состоявшегося идеолога и, наоборот, приписыванием вовлекаемому идеологической незрелости, проявляющейся в растерянности, нерешительности, ведомости адресата передаваемого диалога;

- реализацией образа застывшей идеи, воспроизводимой как универсальный «рецепт» изменения миропорядка, не знающей себе альтернатив и не вступающей в диалог с другими идеями, способными расширить кругозор вовлекаемого;

- выдвижением сюжетной ситуации диалога (исключительной, критической ситуации) как фактора, создающего необходимые условия для проведения агитации;

- использованием приемов контролируемого получения коммуникативных реакций для некритичного принятия идей группы. Представим более развернутое описание таких приемов.

Структурная организация вовлекающегго диалога. Несомненно, основная функциональная нагрузка в реализации агитационноинструктирующей цели высказывания приходится на композиционно-тематическую структуру диалога, включенного в контекст рассказа. Передаваемая рассказчиком беседа отражает способ упорядоченного представления диалогических ходов, направленных на то, чтобы: а) поставить проблему недолжного положения дел в исламе; б) призвать к действиям для восстановления порядка, обеспечивающего интересы адресатов; в) указать на силу, которая способна восстановить необходимый порядок; г) побудить адресатов присоединиться к партии, деятельность которой отвечает их чаяниям и интересам. Соответственно, в технике построения диалога прослеживается намерение адресанта инициировать присоединение реципиента к организации посредством обещания желаемого блага (беспрепятственного доступа к святыням), которое, однако, можно получить только пу- тем включения в коллективную деятельность (вместе с партией "Хизб ут-Тахрир альИслами») и при соблюдении обязанностей, обеспечивающих успех дела (в качестве обязанностей называется следующее: работа в рядах партии «Хизб ут-Тахрир аль-Ислами»; устранение грании между государствами с традиционно исламским вероисповеданием; освобождение Палестины; ликвидаиия нынешних правительств и назначение одного правителя; создание единого мусульманского государства и т. д.).

Использование реплик, провоцирующих желательные коммуникативные реакции. Направляемый характер беседы предполагает контроль за реакциями адресата (их стимулирование и управление ими), чему способствует техника провокации, посредством которой автор получает желаемую обратную связь, предопределяющую дальнейшие аргументативные ходы и реплики субъекта воздействия.

Контроль за реакциями устанавливается на уровне коммуникативно-семиотической организации стимульных высказываний путем использования ритуализованных реплик, вопросов, побуждений.

Например, используются вопросы, актуализующие такое положение вещей в мире, опровержение которого бессмысленно (Почему вы лишились возможности читать намаз в аль-Акъса и довольствуетесь этим, в то время как намаз в ней подобен тавафу? И что вы сделали, чтобы устранить препятствие? Вы устранили его?).

Показательно и включение в текст императивных высказываний, организация которых ограничивает произвольный характер ответных речевых действий: призыв Вставайте, пойдем сейчас в аль-Акъса! является заведомо неэффективным речевым актом (Они ответили: «Нет, мы не можем»), поскольку при его производстве преднамеренно нарушается подготовительное условие успешности речевого акта: выдвигаемая коммуникативная цель (побуждение немедленно идти из Мекки в Иерусалим) формулируется без учета объективного положения дел (наличия границ, препятствующих свободному перемещению мусульман из одной святыни в другую).

Особенности аргументации и состояния приемлемости аргумента. Управле- 
ние реакциями собеседников, связанное с соблюдением / несоблюдением условий успешности регулирующих речевых актов, позволяет агитатору (по представлениям автора текста) включать в диалог идеи, значимые для сообщества, на фоне устанавливающегося консенсуса с адресатом. В качестве примера приведем один из фрагментов Объекта:

«...А как быть, если аль-Акъса оккупирована Израилем? Знаете ли вы, что я на протяжении десяти лет не читаю намаз в аль-Акъса в то время, как я живу на расстоянии получаса езды на автомобиле? Поистине, евреи, окружив ее, не дают мусульманам читать намаз в ней!». Они сказали: «Пусть Аллах поможет вам!». И стали читать ду'а против евреев и взывать о помощи палестинцам. Они сказали: «Наши сердца с вами и мы молимся за вас!». Я сказал им: «Вы думаете, что мольбы для Палестины достаточно, чтобы освободить ее?». Они ответили: «Нет!». Я спросил у них: «Достаточно ли чтения Корана, чтобы освободить ее?». Они ответили: «Нет!». И я сказал: «В таком случае, как освободить её, когда на неё набросились народы, помогая евреям в её оккупации? Мое послание вам заключается в том, что Палестина не для жителей Палестины, ибо мы, жители Палестины, не можем освободить ее. Мы в Палестине не нуждаемся в еде, одежде, лекарствах и скорой помощи, а нуждаемся в многочисленной армии, которая освободит её. Палестина не нуждается в застраивании, а нуждается в освобождении!»

Пример демонстрирует, что воздействие на адресата осуществляется поэтапно:

сначала адресант обеспечивает эмоционально-рассудочное принятие идеи о необходимости освобождения Палестины, провоцируя выражение солидарности с ее народом (Они сказали: "Пусть Аллах поможет вам!». И стали читать ду'а против евреев и взывать о помощи палестинцам. Они сказали: «Наши сердиа с вами и мы молимся за вас!») и вынуждая согласиться с тем, что для освобождения Палестины недостаточно обращений к Аллаху и чтения Корана (Я сказал им: «Bы думаете, что мольбы для Палестины достаточно, чтобы освободить ее?». Они ответили: «Нет!». Я спросил у них: «Достаточно ли чтения Корана, чтобы освободить ее?». Они ответили: «Нет!»);

затем, обеспечив себя субъективными предпосылками для выдвижения приемлемого тезиса (то есть создав необходимую атмосферу консенсуса), адресант призывает удовлет- ворить потребность жителей Палестины в многочисленной армии, способной отвоевать захваченную Израилем территорию (...Мое послание вам заключается в том, что... Mbl в Палестине... нуждаемся в многочисленной армии, которая освободит её. Палестина... нуждается в освобождении!).

\section{Заключение}

Дискурсивный анализ позиции вовлечения выявил отдельные аспекты функционирования текстовых структур в изначально асимметричной коммуникативной среде. Так, стало очевидно, что адаптация жанра к задачам вовлечения, свойственным определенному институциональному контексту, подчинена корпоративным стандартам, принятым в радикальном сообществе для установления связи с аут-группой и обучения представителей ин-группы. В частности, особой значимостью характеризуются сценарии фонового вовлечения и расположения первичной аудитории. Будучи совмещенными в рамках рассматриваемого Объекта, они демонстрируют ситуативную предрасположенность жанрового ресурса к преобразованию: а) для передачи интенций, свойственных в большей степени монологической речи (см. интенции побуждения к коллективной деятельности, инструктирования); б) наделения речевого воздействия чертами предсказуемости и регулируемости; в) трансляции готовой, идеологически окрашенной «истины», приводящей к усилению значимости референтной группы и отрицанию ценности какой-либо иной общности.

Исследование опосредованной политической коммуникации с точки зрения ее интерперсональных характеристик, сфокусированных в понятии «позиция вовлечения», представляется весьма перспективным для разработки диагностического комплекса, с опорой на который возможно проведение судебных лингвистических экспертиз по делам, связанным с подстрекательством в деятельность экстремистской (террористической) направленности.

\section{ПРИМЕЧАНИЯ}

${ }^{1}$ Статья выполнена в рамках гранта РФФИ № 18-012-00574 «Лингвокультурные доминанты ле- 
гитимных / нелегитимных политических дискурсивных практик в пространстве русскоязычной коммуникации: типологическое исследование».

This study was carried out as part of RFBR grant No. 18-012-00574 "Linguo-cultural dominants of legitimate / illegitimate political discursive practices in the Russian-speaking communication space: a typological study".

${ }^{2}$ Ряд методологических подходов и отдельные метадискурсивные техники вовлечения были описаны в работе: [Катышев, 2019].

\section{СПИСОК ЛИТЕРАТУРЫ}

Бахтин М. М., 1979. Проблемы поэтики Достоевского. М. : Сов. Россия. 320 с.

Боженкова Н. А., Катышев П. А., Ионова С. В., Афанасьева Э. М., Саакян Л. Н., 2019. Русский политический дискурс в фокусе лингвоэкологии // Вестник Волгоградского государственного университета. Серия 2, Языкознание. Т. 18, № 3. С. 76-92. DOI: https://doi.org/ 10.15688/jvolsu2.2019.3.6.

Гуляева М. А., 2016. Теоретические основы изучения вовлеченности в коммуникацию // Известия Волгоградского государственного педагогического университета. № 9-10 (113). C. 65-69.

Катышев П. А., 2019. Жанр в дискурсивной практике вовлечения: критическое исследование политической коммуникации // Русский язык за рубежом. № 4. С. 33-40.

Кравченко А. И., Поликарпов В. А., Науменко Л. И., 2019. Группа референтная // Гуманитарная энциклопедия : Концепты. Центр гуманитарных технологий. URL: https://gtmarket.ru/ concept/6931 (дата обращения: 28.09.2019).

Олсон М., 1995. Логика коллективных действий. Общественные блага и теория групп. М. : Фонд Экон. Инициативы. 165 с.

Селиванова М. А., 2010. К вопросу о понятии вовлечения несовершеннолетних в совершение преступлений // Известия Иркутской государственной экономической академии. № 2 (70). C. 146-149.

Хазимуллина Е. Е., 2016. Механизм речевого вовлечения в деятельность экстремистских организаций // Acta Linguistica Petropolitana. Труды института лингвистических исследований. T. 12, № 3. C. 453-469.

Araeva L. A., Katyshev P. A., Osadchiy M. A., Olenev S. V., 2018. Recontextualization of the Religious Term 'Ziyarat': Critical Discourse Study // European Journal of Science and Theology. Vol. 14 (5). P. 137-147.
Bhatia A., 2011. Building Community in International Politics: A Study of Political Press Conferences // Ibérica. Vol. 21. P. 117-140.

Engagement in Professional Genres, 2019. Pragmatics $\&$ Beyond New Series. xiv, 373 p. DOI: 10.1075/ pbns.301.

Hyland K., 2005. Stance and Engagement: A Model of Interaction in Academic Discourse // Discourse Studies. Vol. 7 (2). P. 173-192.

Hyland K., 2010. Constructing Proximity: Relating to Readers in Popular and Professional Science // Journal of English for Academic Purposes. Vol. 9 (2).P. 116-127.DOI: 10.1016/j.jeap.2010.02.003.

Hyland K., 2017. Metadiscourse: What is it and Where Is It Going? // Journal of Pragmatics. Vol. 113. P. 16-29. DOI: 10.1016/j.pragma.2017.03.007.

Hyland K., Jiang F., 2016. "We Must Conclude That...": A Diachronic Study of Academic Engagement // Journal of English for Academic Purposes. Vol. 24. P. 29-42. DOI: 10.1016/ j.jeap.2016.09.003.

Jayyusi L., 1984. Categorization and the Moral Order. L. : Routledge \& Kegan Paul. 275 p.

Leudar I., Marsland V., Nekvapil J., 2004. On Membership Categorization: 'Us', 'Them'and'Doing Violence' in Political Discourse // Discourse \& Society. Vol. 15 (2-3). P. 243-266. DOI: 10.1177/ 0957926504041019.

Suau-Jiménez F., Dolón R., 2007. The Importance of Metadiscourse in the Genre 'Promotion of Touristic Services and Products': Differences in English and Spanish // Languages for Specific Purposes : Searching for Common Solutions / ed. by D. Galová. [S. 1.] : Cambridge Scholars Publishing. P. 71-79.

\section{REFERENCES}

Bakhtin M.M., 1979. Problemy poetiki Dostoevskogo [Problems of Dostoevsky's Poetics]. Moscow, Sovetskaya Rossiya Publ. 320 p.

Bozhenkova N.A., Katyshev P.A., Ionova S.V., Afanasyeva E.M., Saakyan L.N., 2019. Russkij politicheskij diskurs $\mathrm{v}$ fokuse lingvojekologii [Russian Political Discourse in the Focus of Linguistic Ecology]. Vestnik Volgogradskogo gosudarstvennogo universiteta. Seriya 2. Yazykoznanie [Science Journal of Volgograd State University. Linguistics], vol. 18, no. 3, pp. 7692. DOI: https://doi.org/10.15688/jvolsu2.2019.3.6.

Gulyaeva M.A., 2016. Teoreticheskie osnovy izucheniya vovlechennosti v kommunikatsiyu [Theoretical Foundations of Study of Involvement in Communication]. Izvestija Volgogradskogo gosudarstvennogo pedagogicheskogo 
universiteta [Ivzestia of the Volgograd State Pedagogical University], no 9-10(113), pp. 65-69.

Katyshev P.A., 2019 Zhanr v diskursivnoi praktike vovlecheniya: kriticheskoe issledovaniye politicheskoi kommunikatsii [Genre in the Discursive Practice of Involvement: Critical Political Communication Research]. Russkiy yazyk za rubezhom [The Russian Language Abroad], no. 4, pp. 33-40.

KravchenkoA.I., Polikarpov V.A., Naumenko L.I., 2002 2019. Gruppa referentnaya [Reference Group]. Gumanitarnaya entsiklopediya: Kontsepty. Tsentr gumanitarnykh tekhnologii [Humanitarian Encyclopedia: Concepts. Center for Humanitarian Technologies]. URL: https:/gtmarket.ru/concept/ 6931 (accessed 28 September 2019).

Olson M., 1995. Logika kollektivnyh dejstvij. Obshhestvennye blaga i teorija grupp [The Logic of Collective Action: Public Goods and the Theory of Groups]. Moscow, Fond Ekonomicheskoi Initsiativy. 165 p.

Selivanova M.A., 2010. K voprosu o ponyatii vovlecheniya nesovershennoletnikh v sovershenie prestuplenii [About the Term of Juvenile Involvement in the Commission of Crime]. Izvestija Irkutskoj gosudarstvennoj jekonomicheskoj akademii [Izvestiya of Irkutsk State Economics Academy], no2 (70), pp. 146-149.

Khazimullina E.E., 2016. Mekhanizm rechevogo vovlecheniya $\mathrm{v}$ deyatel'nost' ekstremistskikh organizatsii [Mechanism of Speech Involvement by Extremist Organizations]. Acta linguistica Petropolitana. Trudy Instituta lingvisticheskih issledovanij, vol. 12, no. 3, pp. 453-469.

Araeva L.A., Katyshev P.A., Osadchiy M.A., Olenev S.V., 2018. Recontextualization of the
Religious Term 'Ziyarat': Critical Discourse Study. European Journal of Science and Theology, vol. 14 (5), pp. 137-147.

Bhatia A., 2011. Building Community in International Politics: A Study of Political Press Conferences. Ibérica, vol. 21, pp. 117-140.

Engagement in Professional Genres, 2019. Pragmatics $\&$ Beyond New Series. xiv, 373 p. DOI: 10.1075/ pbns.301.

Hyland K., 2005. Stance and Engagement: A Model of Interaction in Academic Discourse. Discourse Studies, vol. 7 (2), pp. 173-192.

Hyland K., 2010. Constructing Proximity: Relating to Readers in Popular and Professional Science. Journal of English for Academic Purposes, vol. 9(2), pp. 116-127.DOI: 10.1016/j.jeap.2010.02.003.

Hyland K., 2017. Metadiscourse: What Is It and Where Is It Going? Journal of Pragmatics, vol. 113, pp. 16-29. DOI: 10.1016/j.pragma.2017.03.007.

Hyland K., Jiang F., 2016. "We Must Conclude That...”: A Diachronic Study of Academic Engagement. Journal of English for Academic Purposes, vol. 24, pp. 29-42. DOI: 10.1016/j.jeap.2016.09.003.

Jayyusi L., 1984. Categorization and the Moral Order. London, Routledge \& Kegan Paul. 275 p.

Leudar I., Marsland V., Nekvapil J., 2004. On Membership Categorization: 'Us', 'Them' and 'Doing Violence' in Political Discourse. Discourse \& Society, vol. 15 (2-3), pp. 243-266. DOI: $10.1177 / 0957926504041019$.

Suau-Jiménez F., Dolón R., 2007. The Importance of Metadiscourse in the Genre 'Promotion of Touristic Services and Products': Differences in English and Spanish. Languages for Specific Purposes: Searching for Common Solutions. [S. 1.], Cambridge Scholars Publishing, pp. 71-79.

\section{Information About the Authors}

Pavel A. Katyshev, Doctor of Sciences (Philology), Professor, Department of General and Russian Linguistics, Pushkin State Russian Language Institute, Akademika Volgina St, 6, 117485 Moscow, Russia, katpa@rambler.ru,https://orcid.org/0000-0002-2492-6495

Natalya A. Bozhenkova, Doctor of Sciences (Philology), Professor, Department of General and Russian Linguistics, Pushkin State Russian Language Institute, Akademika Volgina St, 6, 117485 Moscow, Russia, natalyach@mail.ru, https://orcid.org/0000-0002-2381-5865

\section{Информация об авторах}

Павел Алексеевич Катышев, доктор филологических наук, профессор кафедры общего и русского языкознания, Государственный институт русского языка им. А.С. Пушкина, ул. Академика Волгина, 6, 117485 г. Москва, Россия, katpa@rambler.ru, https://orcid.org/0000-0002-2492-6495

Наталья Александровна Боженкова, доктор филологических наук, профессор кафедры общего и русского языкознания, Государственный институт русского языка им. А.С. Пушкина, ул. Академика Волгина, 6, 117485 г. Москва, Россия, natalyach@mail.ru, https://orcid.org/0000-0002-2381-5865 